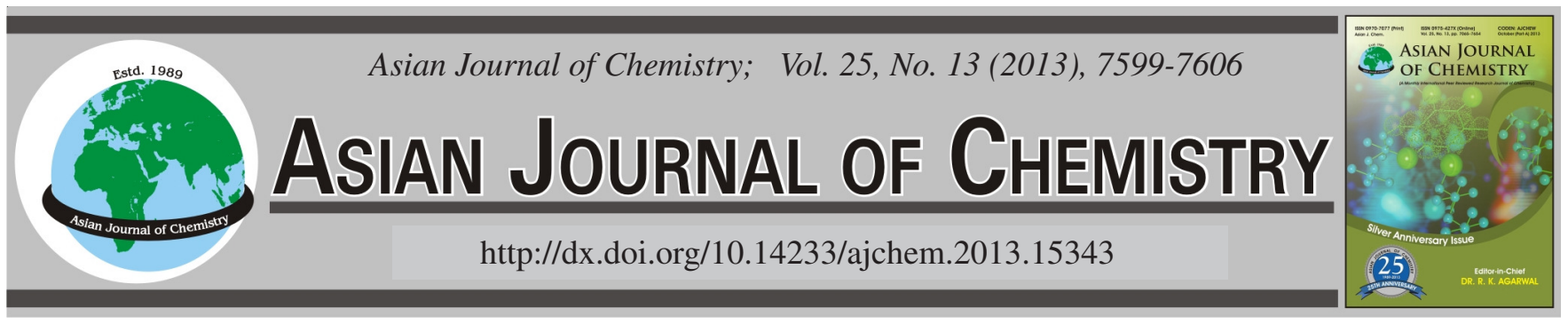

\title{
Design, Development and Optimization of Gastro \\ Retentive Floating Tablets of Cefixime Trihydrate
}

\author{
S. Mohapatra ${ }^{1, *}$, B. BARIK ${ }^{1}$, R.K. KAR ${ }^{2}$, S.K. SAHOO ${ }^{3}$ and B.B. BARIK ${ }^{3}$
}

${ }^{1}$ School of Pharmaceutical Sciences, S'O'A University, Bhubaneswar-751 003, India

${ }^{2}$ Dadhichi College of Pharmacy, Cuttack-754 002, India

${ }^{3}$ University Department of Pharmaceutical Sciences, Utkal University, Bhubaneswar-751 004, India

*Corresponding author: E-mail: dollypharma83@gmail.com

(Received: 18 February 2013;

Accepted: 3 July 2013)

AJC-13761

\begin{abstract}
The purpose of the research was to design and development of gastro retentive floating tablets of cefixime trihydrate by statistical optimization technique and to investigate the effect of formulation variables on drug release characteristics. Guar gum (viscoelastic agents), sodium alginate (gelling agent) and sodium $\mathrm{CMC}$ (channeling agent) were used as independent variables so as to get the optimum formulation by central composite design of response surface methodology taking the parameters time required to release $50 \%$ of drug $\left(\mathrm{t}_{50}\right.$ $\%$ ), drug release at $2 \mathrm{~h}\left(\mathrm{R}_{2 \mathrm{~h}}\right)$ and mean dissolution time as dependent variables. The observed and predicted response of above three parameters are in good agreement shown the maximum coefficient of determination $\left(\mathrm{R}^{2}\right)$. Optimum formulation was found from desirability plot and overlay plot. Least precision was observed when experimental values of the responses were quantitatively compared with predicted values of the optimized formulation. No chemical interaction was observed when FTIR data of pure drug and the optimized formulation (XG21) were compared. From the dissolution data of formulations it was found that all are followed Higuchi's release with a non Fickian diffusion mechanism.
\end{abstract}

Key Words: Gastro retentive floating tablets, Cefixime trihydrate, Response surface methodology, Fickian diffusion.

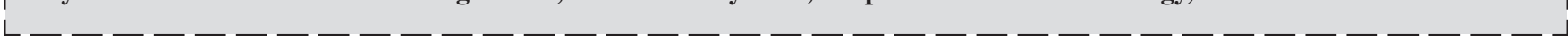

\section{INTRODUCTION}

Gastrointestinal (GI) transit time is one of the several physiological limitations that must be controlled in the development of peroral modified release dosage forms ${ }^{1}$. Intra gastric floating (IGF) drug delivery systems can improve the controlled delivery of drugs that have an absorption window by continuously releasing the drugs for a prolonged period of time before its absorption site, thus ensuring its optimum bioavailability ${ }^{2}$. Several reported methods for the design of gastro retentive systems include mucoadhesive ${ }^{3}$, floating, sedimentation ${ }^{4}$, expansion ${ }^{5}$ and modified shape system. Floating drug delivery systems having low density, that have sufficient buoyancy to float over the gastric contents and remain in the stomach without affecting the gastric emptying rate for a prolonged period. While the system floats over the gastric contents, the drug is released slowly at the desired rate, which results in increased gastric retentive time and reduces fluctuation in plasma drug concentration. Thus, GFDDS is able to prolong the retention time of a dosage form in the stomach, thereby improving the oral bioavailability of the drug.

In the present investigation, cefixime trihydrate (CT) was selected as model drug in the development of the gastro retentive floating tablets (GFT). Cefixime trihydrate is orally active third generation cephalosporin with chemical name (6R,7R)-7[(2Z)-2-(2-amino-1,3-thiazol-4-yl)-2-[(carboxymethoxy) imino]acetamido]-3-ethenyl-8-oxo-5-thia-1-azabicyclo[4.2.0] oct-2-ene-2-carboxylic acid (Fig. 1), active against Entero bacteriaceae, Haemofilia influenzae, Streptococcus pyogenes, Streptococcus pneumoniae, Moraxella, E. coli, Protease, Neisseria gonorrhea and is resistant to many $\beta$-lactamases. Cefixime trihydrate with $\mathrm{pK}_{\mathrm{a}}$ value of 2.5 , a weak acid which will remain unionized at acidic $\mathrm{pH}$ thus increases absorption in the stomach region. The absolute bioavailability of all newer oral cephalosporin is below 50-60\%, which suggests an absorption mechanism through the mucosa with limited capacity ${ }^{6,7}$. The biological half life is $3.0 \pm 0.4 \mathrm{~h}$. Formulation of floating tablet containing cefixime trihydrate as a drug candidate, which would remain in stomach or upper part of gastrointestinal track for prolonged period of time, therefore the maximum drug release is maintained at desired site.

The objective of this study was to systematically investigate the impact of several formulation variables on drug release and buoyancy properties of a gastro retentive floating tablet containing cefixime trihydrate as model drug using response 


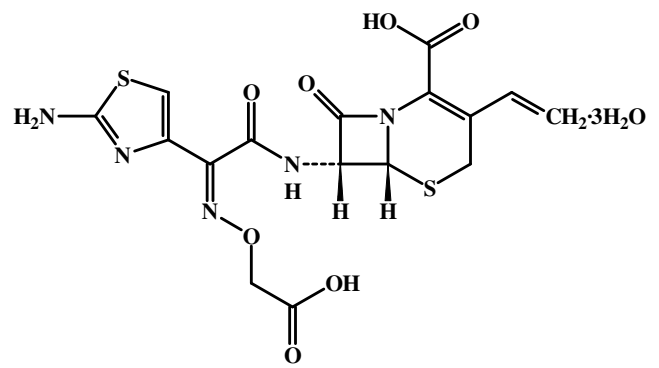

Fig. 1. Structure of cefixime trihydrate

surface methodology (RSM). To achieve this objective, the quantity of different excipients were used as gas generating agent (sodium bicarbonate), swelling agent (cross linked CMC), viscoelastic agent (Guar gum) and a gel forming polymer (sodium alginate) and were selected as independent variables, while the time required to release $50 \%$ of drug $\left(\mathrm{t}_{50} \%\right)$, drug release at $2 \mathrm{~h}\left(\mathrm{R}_{2 \mathrm{~h}}\right)$ and mean dissolution time MDT were taken as dependent variables. The ranges of these formulation variables were chosen based on the results obtained in preliminary studies conducted in our laboratory.

Response surface methododogy is widely employed to optimize formulations with suitable experimental design because it permits a deeper under standing of a process or product and has important applications in establishing the robustness of that product. Central composite design is a progression from factorial designs, which have been widely used in response surface modeling and optimization ${ }^{8}$.

In this study, Design Expert software was used to give information not only on the critical values required to achieve the desired response but also the possible interactions of the selected independent variables on the dependent variables.

\section{EXPERIMENTAL}

Cefixime trihydrate was provided by Lincon Pharmaceutical, Ahmadabad, guar gum, sodium bicarbonate, sodium alginate, sodium CMC were provided by Cipla limited (Goa, India). Lactose, magnesium stearate and other chemicals were analytical grade and used as received.

Experimental design: Response surface methodology (RSM) aims to establish the relative importance of two or more factors and also to indicate whether or not interaction occurs between the factors and thereby affects the magnitude of the response. Central composite design can be used to derive two or more factors. A three-factor $(\mathrm{X} 1, \mathrm{X} 2, \mathrm{X} 3)$, two-level $(-1,+1)$ design can be developed by inclusion of a central point (Table1). Horizontal and vertical lines are drawn through the central point to form the axes of a central composite design. Further experiments are positioned along the axes at a distance from the central point and the points $\mathrm{X} 1=0, \mathrm{X} 2= \pm \alpha, \mathrm{X} 3= \pm \alpha$, when $\mathrm{X} 2=0, \mathrm{X} 1= \pm \alpha, \mathrm{X} 3= \pm \alpha$ and $\mathrm{X} 3=0, \mathrm{X} 2= \pm \alpha, \mathrm{X} 1=$ $\pm \alpha$ are called axial points. For a three-factor design, the domain becomes a circle centered on $(0,0)$ and passing through the factorial points $(-1,-1),(+1,-1)$ and $(+1,+1)$, axial points $(-1,0),(0,+1)$ and $(+1,0)$ and soon.

\section{Methods}

Drug-excipient compatibility: The infrared spectra of pure drug (cefixime trihydrate), binary mixture of drug and

\begin{tabular}{|c|c|c|c|}
\hline \multicolumn{4}{|c|}{$\begin{array}{c}\text { TABLE-1 } \\
\text { EXPERIMENTAL RANGE AND LEVEL } \\
\text { OF INDEPENDENT VARIABLES }\end{array}$} \\
\hline \multirow{2}{*}{ Coded } & \multirow{2}{*}{ Variable } & \multicolumn{2}{|c|}{ Range and level } \\
\hline & & -1 & +1 \\
\hline A & Guar gum (\%) & 8 & 10 \\
\hline B & Sodium alginate $(\%)$ & 5 & 10 \\
\hline $\mathrm{C}$ & Sodium CMC (\%) & 5 & 10 \\
\hline
\end{tabular}

each excipient (1:1), optimized formulations and placebo were recorded between 600 and $4000 \mathrm{~cm}^{-1}$ by FT-IR spectrometer (JASCO FT/IR-4000, Japan) using KBr pellet technique.

Formulations: Floating matrix tablet formulations containing $50 \%$ of CT were prepared by wet granulation method. Cefixime trihydrate (CT) $200 \mathrm{mg}$ was mixed with the required quantities of polymer blend, guar gum (8-10\%), sodium CMC $(5-10 \%)$, sodium alginate $(5-10 \%)$ with sodium bicarbonate $(15 \%)$ and lactose q.s. to made $400 \mathrm{mg} / \mathrm{tab}$ by geometric mixing (Table-2). Damp mass of the mixture was prepared by aqueous solution, followed by wet sieving in 12 $\mathrm{mm}$ sieve. Then dried up to $1 \mathrm{~h}$ at $40^{\circ} \mathrm{C}$ followed by dry sieving. The dried granules were lubricated with magnesium stearate (2\%) and compressed on a 10-station rotary tablet machine (Rimek, Ahmadabad, India) using a $10 \mathrm{~mm}$ standard flat-face punch.

TABLE-2

PRESENTATION OF REAL VALUES OF 2 LEVELS FOR THE CENTRAL COMPOSITE DESIGN

\begin{tabular}{cccc}
\hline Formulations & Guar gum $(\%)$ & Sod. alginate $(\%)$ & Sod. CMC $(\%)$ \\
\hline XG1 & 8 & 5 & 5 \\
XG2 & 10 & 5 & 5 \\
XG3 & 8 & 10 & 5 \\
XG4 & 10 & 10 & 5 \\
XG5 & 8 & 5 & 10 \\
XG6 & 10 & 5 & 10 \\
XG7 & 8 & 10 & 10 \\
XG8 & 10 & 10 & 10 \\
XG9 & 9 & 7.5 & 7.5 \\
XG10 & 9 & 7.5 & 7.5 \\
XG11 & 9 & 7.5 & 7.5 \\
XG12 & 9 & 7.5 & 7.5 \\
XG13 & 7.318207 & 7.5 & 7.5 \\
XG14 & 10.68179 & 7.5 & 7.5 \\
XG15 & 9 & 3.295518 & 7.5 \\
XG16 & 9 & 11.70448 & 7.5 \\
XG17 & 9 & 7.5 & 3.295518 \\
XG18 & 9 & 7.5 & 11.70448 \\
XG19 & 9 & 7.5 & 7.5 \\
XG20 & 9 & 7.5 & 7.5 \\
\hline
\end{tabular}

Evaluation of the GFT: The prepared tablets were evaluated for parameters like hardness (Monsanto hardness tester), friability, weight variation, thickness, water uptake, in vitro drug release, in vitro floating lag time and total buoyancy time.

In vitro buoyancy studies: The in vitro buoyancy was determined by measuring floating lag times and duration of buoyancy according to the method described by Rosa et al. ${ }^{9}$. The tablets were placed in a $100 \mathrm{~mL}$ beaker containing 100 $\mathrm{mL} 0.1 \mathrm{~N} \mathrm{HCl}$. The time required for the tablet to rise to the surface and float was taken as the floating lag time. The time for which tablets kept floating was termed as 'buoyancy time' of the tablets which was determined for all the formulations. 
In vitro release studies: The release of drug was studied using USP Type II dissolution apparatus using $900 \mathrm{~mL} 0.1 \mathrm{~N}$ $\mathrm{HCl}$ as dissolution media maintained at $37 \pm 0.5{ }^{\circ} \mathrm{C}$ with rotation speed of $50 \mathrm{rpm}$. Aliquots of $1 \mathrm{~mL}$ were collected at pre-determined time intervals and were replenished with equivalent volume of fresh medium. The samples were filtered and diluted to a suitable concentration with $0.1 \mathrm{~N} \mathrm{HCl}$. They were analyzed by using UV-visible double beam spectrophotometer at $278 \mathrm{~nm}$ (V-670, Jasco, Japan). The results were expressed as mean \pm SD $(n=3)$. Cumulative percentage drug release was calculated using an equation obtained from standard curve. The times for $50 \%$ drug release, drug released at $2 \mathrm{~h}$ were calculated based on the Korsmeyer and Peppas model ${ }^{10}$.

Release profile analysis: Several mathematical models can be tested to determine which best describes the kinetics and mechanism of drug release from floating tablets. In the present study, the in vitro drug release data was fitted to the following mathematical models:

Zero order (eqn. 1) as cumulative percentage of drug release vs. time, 1 st order (eqn. 2) as log amount remaining to be released versus time and Higuchi model (eqn. 3) cumulative percentage of drug release vs. square root of time

$$
\mathrm{C}=\mathrm{K}_{0} \mathrm{t}
$$

where $\mathrm{K}_{0}$ is the zero order rate constant, a graph of concentration versus time would yield a straight line with a slope equal to $\mathrm{K}_{0}$ and intercept the origin of the axes ${ }^{11}$.

$$
\log \mathrm{C}=\log \mathrm{C}_{0}-\mathrm{K}_{1} \frac{\mathrm{t}}{2.303}
$$

where $\mathrm{C}_{0}$ is the initial concentration of drug, $\mathrm{K}_{1}$ is the 1 st order rate constant ${ }^{12}$

$$
\mathrm{Q}=\mathrm{K}_{\mathrm{h}} \mathrm{t}^{1 / 2}
$$

where $K_{h}$ is the constant reflecting design variables of the system and $t$ is the time in hours. Hence drug release is proportional to the reciprocal of the time ${ }^{13}$.

To evaluate the drug release with change in the surface area and diameter of the particles/tablets the data were also plotted using the Hixson-Crowell cube root law

$$
\mathrm{Q}_{0}^{1 / 3}-\mathrm{Q}_{\mathrm{t}}^{1 / 3}=\mathrm{K}_{\mathrm{hc}} \mathrm{t}
$$

where $Q_{t}$ is the amount of drug to be released in time $t, Q_{0}$ is the initial amount of drug in the tablet and $\mathrm{K}_{\mathrm{hc}}$, is the rate constant for Hixson-Crowell rate equation ${ }^{14}$.

Mechanism of drug release: To evaluate the mechanism of drug release from floating matrix tablets, data of drug release was plotted in Korsmeyer et al's equation (eqn. 5) as log cumulative $\%$ of drug released vs. log time and the exponent 'n' value was calculated through the slope of the straight line.

$$
\frac{\mathrm{M}_{\mathrm{t}}}{\mathrm{M}_{\infty}}=\mathrm{Kt}^{\mathrm{n}}
$$

where $M_{t} / M_{\infty}$ are the fractional solute released, $t$ is the released time; $\mathrm{K}$ is the kinetic constant of drug polymer system and ' $n$ ' is an exponent that characterizes the mechanism of drug release $^{15}$.

For a cylindrical matrix tablets, if the exponent $\mathrm{n}=0.45$, then the drug release mechanism is Fickian diffusion and if $0.45<\mathrm{n}<0.89$ then it is non Fickian diffusion. An exponent value 0.89 indicative of case II transport or typical zero order release $^{16}$.

Mean dissolution time (MDT) value is used to characterize drug release rate from a dosage form and indicates the drug release retarding efficiency of polymer.

$$
\operatorname{MDT}=\frac{\sum_{\mathrm{j}=1}^{\mathrm{n}} \hat{\mathrm{t}} \Delta \mathrm{Mj}}{\sum_{\mathrm{j}=1}^{\mathrm{n}} \Delta \mathrm{Mj}}
$$

where $\mathrm{j}$ is the sample number, $\mathrm{n}$ is the number of dissolution sample times, $\hat{t}_{j}$ is the time at midpoint between $t_{j}$ and $t_{j-1}$ (easily calculated with the expression, $\left(t_{j}+t_{j-1}\right) / 2$ ) and $\Delta \mathrm{M}_{j}$ is the additional amount of drug released between $t_{j}$ and $t_{j-1}{ }^{17}$.

Statistical analysis and optimization: Statistical analysis of the data and optimization polynomial models including linear, interaction and quadratic terms were generated for all the response variables using Design Expert software. The data were used to generate the study design and response surface and contour plots. The best fitting model was selected based on the comparisons of several statistical parameters including the coefficient of variation $(\mathrm{CV})$, the coefficient of determination $\left(\mathrm{R}^{2}\right)$, adjusted coefficient of determination (adjusted $\mathrm{R}^{2}$ ) and predicted coefficient of determination (predicted $\mathrm{R}^{2}$ ) provided by Design Expert software. In addition, statistical analysis like analysis of variance (ANOVA) to identify significant effect of factors on response, regression coefficients, $\mathrm{F}$ test and $\mathrm{P}$ values were also calculated with the software.

The relationship between the dependent and independent variables was further elucidated using response surface plots. These plots are useful to study the effects of various factors on the response at a given time and to predict the responses of dependent variables at intermediate levels of independent variables. Subsequently, a numerical optimization technique using the desirability approach and a graphical optimization technique using overlay plots were used to generate new formulations with the desired responses.

Validation of the experimental design: To validate the chosen experimental design, the experimental values of the responses were quantitatively compared with predicted values and the relative error $(\%)$ calculated using the following equation (eqn. 7):

Relative error (\%)

$$
=\frac{(\text { Predicted value }- \text { Experiment value })}{\text { Predicted value }} \times 100 \%
$$

\section{RESULTS AND DISCUSSION}

In vitro buoyancy studies: All gastro retentive floating tablets passed physicochemical tests for weight variation, drug content and friability. Floating lag time of all formulations was within the range 8-16 min (Table-3). All formulations floated in the $0.1 \mathrm{~N} \mathrm{HCl}$ for more than $11 \mathrm{~h}$ showing good matrix integrity during this extended period of time. From the data it was revealed that as the concentration of polymer increased, the floating lag time decreased due to the increasing hydrophilic nature of the polymer allowing penetration of liquid 


\begin{tabular}{cccccc}
\hline \multicolumn{6}{c}{ TABLE-3 } \\
\multicolumn{7}{c}{ OBSERVED RESPONSE OF THE FORMULATIONS } \\
IN CENTRAL COMPOSITE DESIGN \\
\hline Formulations & $\begin{array}{c}\mathrm{t}_{50 \%} \\
(\mathrm{~h})\end{array}$ & $\begin{array}{c}\mathrm{R}_{2 \mathrm{~h}} \\
(\%)\end{array}$ & $\begin{array}{c}\text { MDT } \\
(\mathrm{h})\end{array}$ & $\begin{array}{c}\text { Floating lag } \\
\text { time (min) }\end{array}$ & $\begin{array}{c}\text { Floating lag } \\
\text { time (h) }\end{array}$ \\
\hline XG1 & 4.25 & 36.22 & 4.48 & 8 & 11 \\
XG2 & 4.542 & 31.487 & 4.99 & 15 & 14 \\
XG3 & 4.272 & 31.97 & 4.7 & 12 & 12 \\
XG4 & 4.687 & 29.636 & 5.1 & 17 & 12 \\
XG5 & 4.231 & 33.286 & 4.69 & 11 & 11 \\
XG6 & 4.651 & 29.892 & 4.934 & 13 & 12 \\
XG7 & 4.657 & 29.884 & 4.797 & 13 & 13 \\
XG8 & 5.23 & 27.349 & 5.1 & 16 & 14 \\
XG9 & 5.01 & 30.9 & 4.722 & 12 & 13 \\
XG10 & 5.021 & 31.01 & 4.699 & 10 & 11 \\
XG11 & 4.99 & 30.898 & 4.71 & 14 & 12 \\
XG12 & 4.989 & 31.896 & 4.703 & 11 & 13 \\
XG13 & 4.55 & 33.67 & 4.11 & 6 & 11 \\
XG14 & 5.199 & 30.12 & 4.77 & 18 & 13 \\
XG15 & 4.7 & 30.8 & 4.67 & 10 & 14 \\
XG16 & 5.12 & 29.64 & 4.801 & 9 & 12 \\
XG17 & 4.65 & 31.6 & 4.65 & 12 & 13 \\
XG18 & 5.023 & 28.78 & 4.8 & 8 & 10 \\
XG19 & 5.1 & 31.02 & 4.54 & 12 & 14 \\
XG20 & 5.01 & 30.99 & 4.56 & 11 & 13 \\
\hline
\end{tabular}

through pores formed on the surface of the tablet and the total floating time increased due to swelling of the tablet which keeps it intact for a longer period of time ${ }^{18,19}$.

In vitro dissolution studies: The percentage of cefixime trihydrate released from the prepared gastro retentive floating tablets formulations both in factorial, central and axial types are shown in Fig. 2. The in vitro release of cefixime trihydrate from the formulations XG1, 5 and 13 reached $100 \%$ in less than $10 \mathrm{~h}$; but rest of the formulations released the drug up to $12 \mathrm{~h}$. Further, it was found that increased the concentration of polymer decreased the drug release in formulations XG2, 4, 6,8 and 14 , this attribution due to the formulation containing large concentration of high viscosity polymers guar gum induced formation of strong viscous gel layer that leads to decreased water diffusion into the tablet matrix which results in decrease drug release. The gel strength of the swollen matrix formulation might be too high to release the drug from the formulation. On exposure to the dissolution fluids, the guar gum is hydrated and forms a viscous gel layer that slows down further entry of dissolution fluids towards the core of tablets. The hydration of guar gum is independent of the $\mathrm{pH}$ of the dissolution medium ${ }^{20}$. Moreover, incorporation of sodium alginate increasing the gelling characteristics which attributed longer tortuous path thus provides more diffusion path length of the dissolved drug. Hence providing diffusion predominant drug release rather than erosion. Sodium CMC was used as a channeling agent, which guides water penetration into the tablet by forming pores due to its swelling property.

Release kinetics mechanism: Results of fitting the dissolution profiles to the various kinetic models like zero order, 1st order, Higuchi, Hixson, Korsemeyer and Peppas are given in Table-4. Release data of all formulations are best fit with Higuchi's release mechanism. Though the release exponent (n) of different formulations are within 0.55-0.65 which are close approximation to 0.5 reflecting diffusion predominant characteristics of drug release rather than erosion of the polymer.
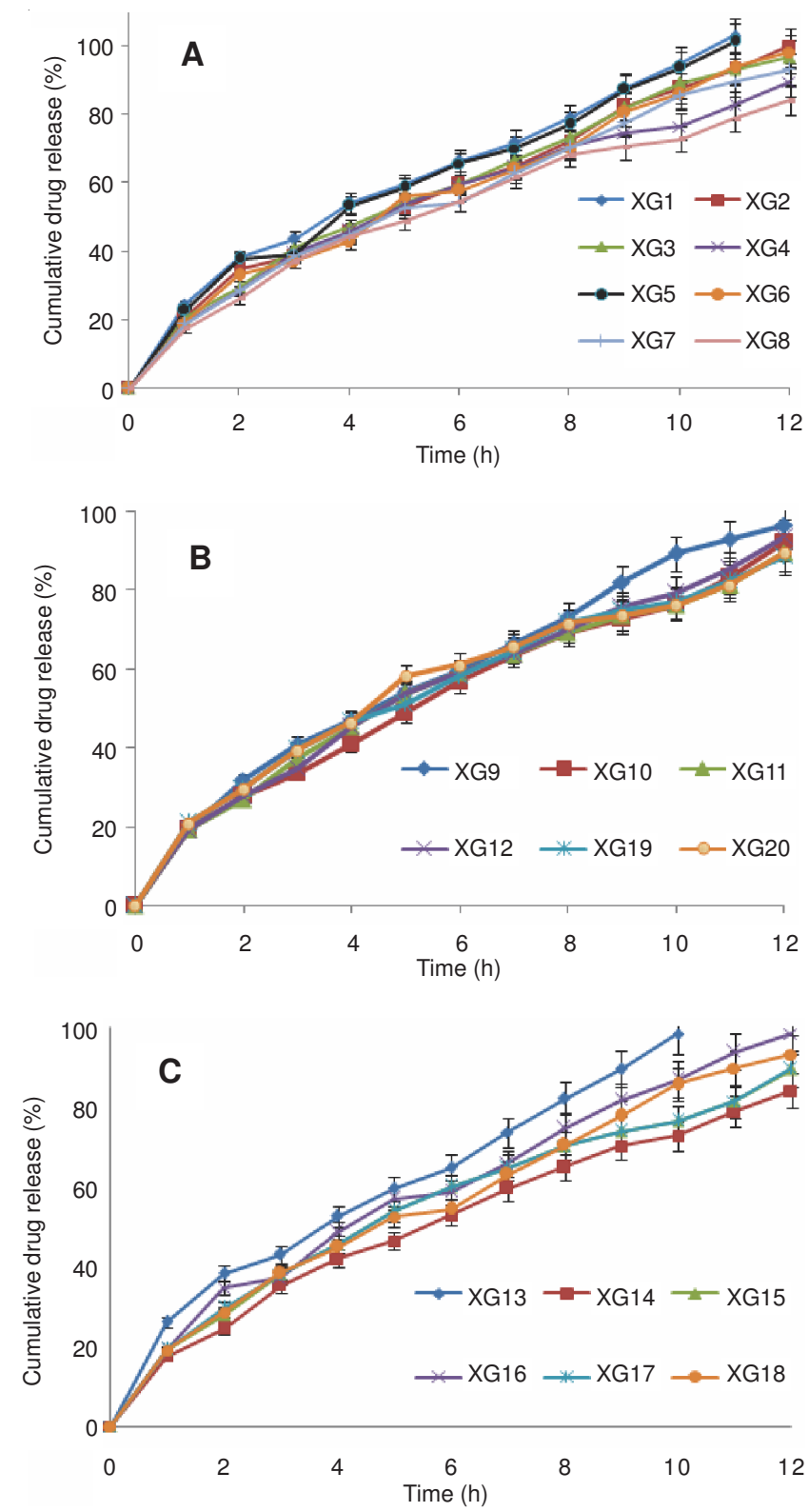

Fig. 2. Dissolution profile of different floating tablets, A; factorial type, $\mathrm{B}$; central type, $\mathrm{C}$; axial type

Data analysis: All responses were fitted to linear, interaction or quadratic models using Design Expert software. A quadratic model is suggested for time required to release $50 \%$ of drug $\left(\mathrm{t}_{50} \%\right.$, mean dissolution time (MDT) and linear model for drug release at $2 \mathrm{~h}\left(\mathrm{R}_{2 \mathrm{~h}}\right)$. All dependent variable responses are shown in Table-3.

Twenty formulations were prepared using different polymers as per the central composite design using design expert software. The $\mathrm{F}$ values for $\mathrm{t}_{50 \%}, \mathrm{R}_{2 \mathrm{~h}}$ and mean dissolution time were found to be 26.54, 22.31 and 61.25, respectively (Table-5) indicating that the models are significant. The values of Prob $>\mathrm{F}$ were found to be 0.05 for all responses again indicating that the models are significant. Further the response observation of interactive term of coded unit $\mathrm{AB}, \mathrm{AC}, \mathrm{BC}, \mathrm{A}^{2}, \mathrm{~B}^{2}$ and $\mathrm{C}^{2}$ of both $\mathrm{t}_{50} \%$ and mean dissolution time having quadratic model and $\mathrm{A}, \mathrm{B}$ of $\mathrm{R}_{2 \mathrm{~h}}$ having linear model are found significant model term. Moreover the lack of fit $F$ values of the above three parameters are $9.57,5.96$ and 18.36 , respectively suggesting 
TABLE-4

OBSERVED RESPONSE OF THE FORMULATIONS IN CENTRAL COMPOSITE DESIGN

\begin{tabular}{|c|c|c|c|c|c|c|c|c|}
\hline \multirow{2}{*}{ Formulations } & \multicolumn{2}{|c|}{ Zero order } & \multicolumn{2}{|c|}{ First order } & \multirow{2}{*}{$\frac{\text { Higuchi }}{\mathrm{R}^{2}}$} & \multirow{2}{*}{$\frac{\text { Hixson-Crowell }}{\mathrm{R}^{2}}$} & \multicolumn{2}{|c|}{ Peppas } \\
\hline & $\mathrm{k}_{0}$ & $\mathrm{R}^{2}$ & $\mathrm{k}_{1}$ & $\mathrm{R}^{2}$ & & & $\mathrm{n}$ & $\mathrm{R}^{2}$ \\
\hline XG1 & 8.203 & 0.963 & 0.244 & 0.899 & 0.985 & 0.964 & 0.568 & 0.993 \\
\hline XG2 & 7.525 & 0.975 & 0.211 & 0.918 & 0.976 & 0.968 & 0.615 & 0.987 \\
\hline XG3 & 7.505 & 0.972 & 0.248 & 0.905 & 0.982 & 0.971 & 0.631 & 0.995 \\
\hline XG4 & 6.651 & 0.951 & 0.161 & 0.968 & 0.992 & 0.987 & 0.614 & 0.997 \\
\hline XG5 & 8.205 & 0.996 & 0.232 & 0.91 & 0.979 & 0.965 & 0.605 & 0.985 \\
\hline XG6 & 7.508 & 0.976 & 0.262 & 0.824 & 0.973 & 0.939 & 0.643 & 0.987 \\
\hline XG7 & 7.239 & 0.974 & 0.202 & 0.936 & 0.978 & 0.978 & 0.645 & 0.995 \\
\hline XG8 & 6.364 & 0.954 & 0.138 & 0.987 & 0.99 & 0.987 & 0.631 & 0.995 \\
\hline XG9 & 7.551 & 0.973 & 0.248 & 0.906 & 0.982 & 0.972 & 0.654 & 0.997 \\
\hline XG10 & 6.649 & 0.952 & 0.161 & 0.965 & 0.991 & 0.986 & 0.618 & 0.996 \\
\hline XG11 & 6.663 & 0.954 & 0.162 & 0.966 & 0.992 & 0.987 & 0.623 & 0.997 \\
\hline XG12 & 6.644 & 0.953 & 0.161 & 0.965 & 0.991 & 0.986 & 0.618 & 0.996 \\
\hline XG13 & 8.619 & 0.964 & 0.304 & 0.788 & 0.981 & 0.923 & 0.562 & 0.985 \\
\hline XG14 & 6.415 & 0.968 & 0.138 & 0.983 & 0.986 & 0.994 & 0.643 & 0.996 \\
\hline XG16 & 7.496 & 0.969 & 0.267 & 0.864 & 0.981 & 0.952 & 0.637 & 0.989 \\
\hline XG17 & 6.6 & 0.95 & 0.159 & 0.965 & 0.992 & 0.985 & 0.608 & 0.997 \\
\hline XG18 & 7.244 & 0.975 & 0.207 & 0.936 & 0.978 & 0.977 & 0.646 & 0.995 \\
\hline XG19 & 6.595 & 0.946 & 0.163 & 0.971 & 0.993 & 0.987 & 0.586 & 0.997 \\
\hline XG20 & 6.546 & 0.943 & 0.159 & 0.966 & 0.993 & 0.984 & 0.583 & 0.996 \\
\hline
\end{tabular}

TABLE-5

SUMMARY OF ANOVA FOR RESPONSE SURFACE OF THE GFT FORMULATIONS

\begin{tabular}{|c|c|c|c|c|c|c|}
\hline Parameters & Sum square & $\mathrm{df}$ & Mean square & F value & $\mathrm{P}$ value prob $>\mathrm{F}$ & Remark \\
\hline \multicolumn{7}{|c|}{$\mathrm{t}_{50 \%}($ Quadratic model $)$} \\
\hline Model & 1.65 & 9 & 0.18 & 26.54 & $<0.0001$ & Significant \\
\hline Lack of fit & 0.057 & 5 & 0.011 & 9.57 & 0.0241 & Significant \\
\hline \multicolumn{7}{|c|}{$\mathrm{R}_{2 \mathrm{~h}}($ linear model $)$} \\
\hline Model & 54.32 & 3 & 18.11 & 22.31 & $<0.0001$ & Significant \\
\hline Lack of fit & 11.47 & 11 & 1.04 & 5.96 & 0.0496 & Significant \\
\hline Model & 0.74 & 9 & 0.082 & 61.25 & $<0.0001$ & Significant \\
\hline Lack of fit & 0.012 & 5 & 0.003 & 18.36 & 0.0073 & Significant \\
\hline
\end{tabular}

the significant characteristics of above three models (Table-5). The calculated $\mathrm{R}^{2}$ value in the present model is close to 1 indicating a good model. In all cases, the adjusted $\mathrm{R}^{2}$ values are in reasonable agreement with the predicted $R^{2}$ values $(0.9274$ and 0.8423 for $\mathrm{t}_{50} \%, 0.7803$ and 0.6131 for $\mathrm{R}_{2 \mathrm{~h}}$ and 0.9679 and 0.8526 for mean dissolution time). In all the cases precision values were in the range 15-35 (values $>4$ ) indicating an adequate signal and that the model can be used to navigate with in the design space (Table-6).

\begin{tabular}{cccc}
\multicolumn{4}{c}{ TABLE-6 } \\
\multicolumn{4}{c}{ STATISTICAL PARAMETERS FOR THE } \\
RESPONSES OF THE GFT FORMULATIONS \\
\hline Parameters & $\mathrm{t}_{50 \%}$ & $\mathrm{R}_{2 \mathrm{~h}}$ & $\mathrm{MDT}$ \\
\hline Std. Dev. & 0.083 & 0.90 & 0.037 \\
Mean & 4.79 & 31.05 & 4.73 \\
$\mathrm{CV}(\%)$ & 1.73 & 2.90 & 0.78 \\
$\mathrm{R}^{2}$ & 0.9637 & 0.8169 & 0.9839 \\
$\mathrm{Adj}^{2} \mathrm{R}^{2}$ & 0.9274 & 0.7803 & 0.9679 \\
Pred-R & 0.8423 & 0.6131 & 0.8526 \\
Adeq precision & 15.671 & 15.153 & 35.626 \\
\hline
\end{tabular}

The application of response surface methodology yielded the following regression equations (A: xanthan gum, B: sodium alginate, $\mathrm{C}$ : sodium $\mathrm{CMC}$ ): $\mathrm{t}_{50 \%}=5.06+0.20 * \mathrm{~A}+0.14 * \mathrm{~B}+0.12 * \mathrm{C}+0.035^{*} \mathrm{~A} * \mathrm{~B}+$ $0.036 * \mathrm{~A} * \mathrm{C}+0.10 * \mathrm{~B} * \mathrm{C}-0.12 * \mathrm{~A}^{2}-0.11 * \mathrm{~B}^{2}-0.13 * \mathrm{C}^{2}$ $\mathrm{R}_{2 \mathrm{~h}}=31.01-1.39 * \mathrm{~A}-1.02 * \mathrm{~B}-1.00 * \mathrm{C}$

$\mathrm{MDT}=4.62+0.19 * \mathrm{~A}+0.060 * \mathrm{~B}+0.037 * \mathrm{C}-0.003 * \mathrm{~A} * \mathrm{~B}$ $-0.045 * \mathrm{~A} * \mathrm{C}-0.003 * \mathrm{~B} * \mathrm{C}-0.027 * \mathrm{~A}^{2}+0.077 * \mathrm{~B}^{2}+$ $0.073 * \mathrm{C}^{2}$

The contour and response surface plots for all responses of all formulation factors are shown in Figs. 3 and 4. The contour and response plots of the response surface as a function of two factors at a time, with all other factors fixed, are more helpful in understanding both the main and interaction effects of the two factors. Further good correlations between the actual and predicted values were observed using the above statistical model (Fig. 5). $\mathrm{R}^{2}$ (coefficient of determination) values are 0.967, 0.818 and 0.986 for $t_{50 \%}, R_{2 h}$ and mean dissolution time, respectively.

To optimize all the responses with different targets, a multi criteria decision approach (a numerical optimization technique by the desirability function and a graphical optimization technique by the overlay plot) was used (Figs. 6 and 7). The optimized formulation was obtained by applying constraints on dependent variable responses and independent variables. The recommended concentrations of the independent variables were calculated by the Design Expert software from the above 


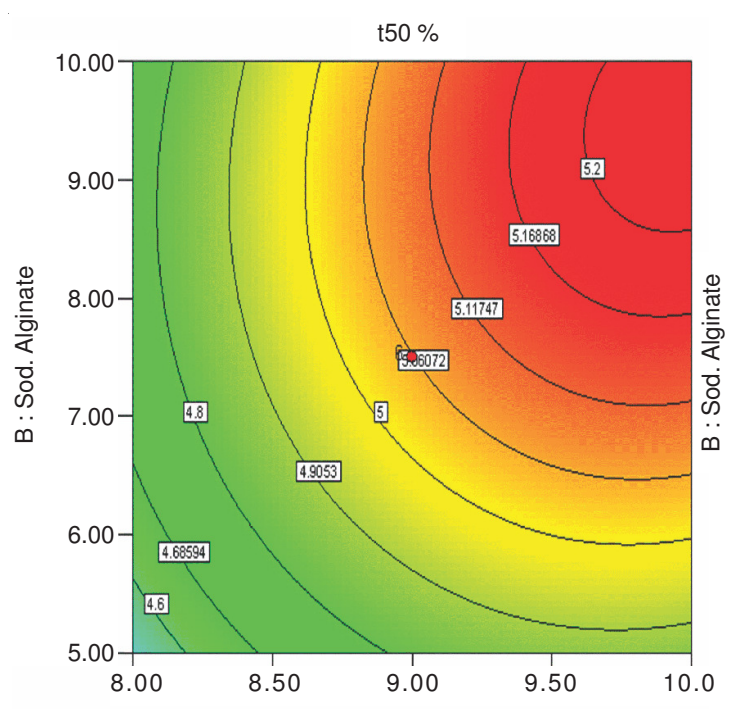

A : Guar Gum

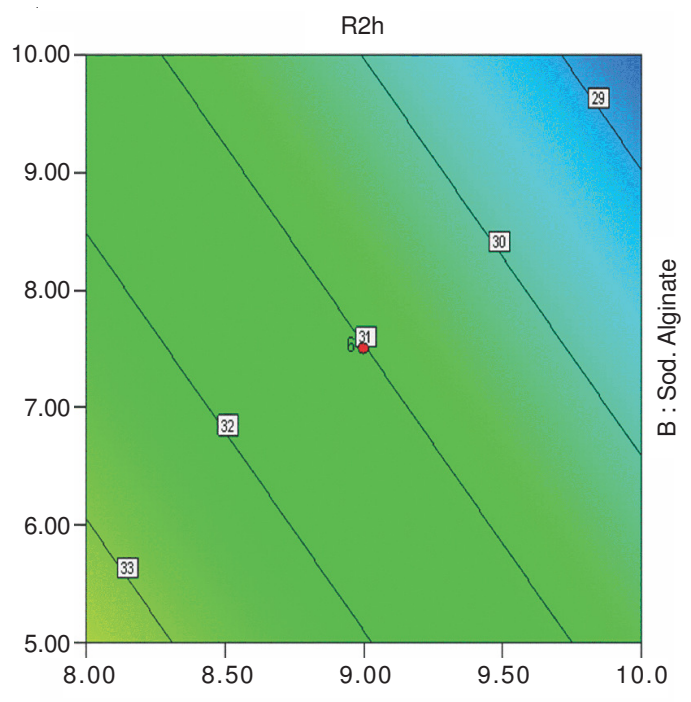

A : Guar Gum

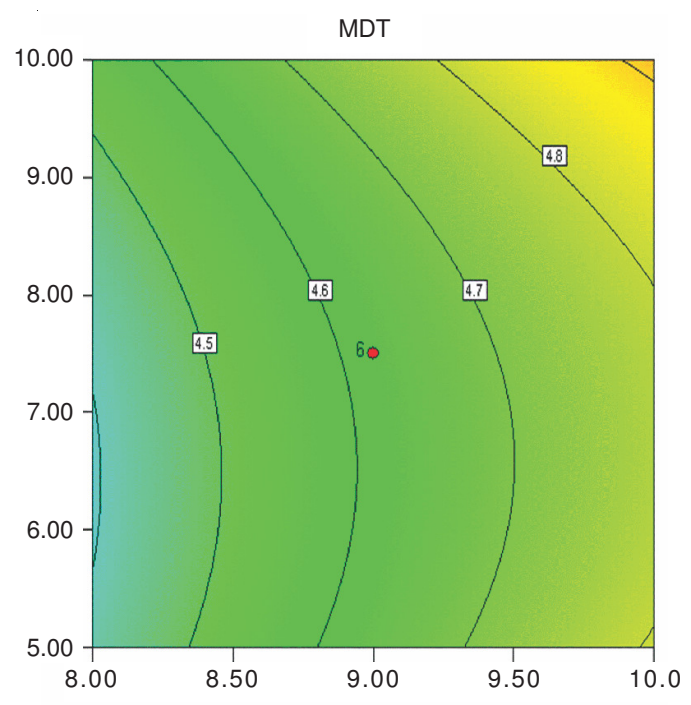

A : Guar Gum

Fig. 3. Contour plots for the response of $t_{50} \%, \mathrm{R}_{2 \mathrm{~h}}$ and mean dissolution time in the change in independent variables
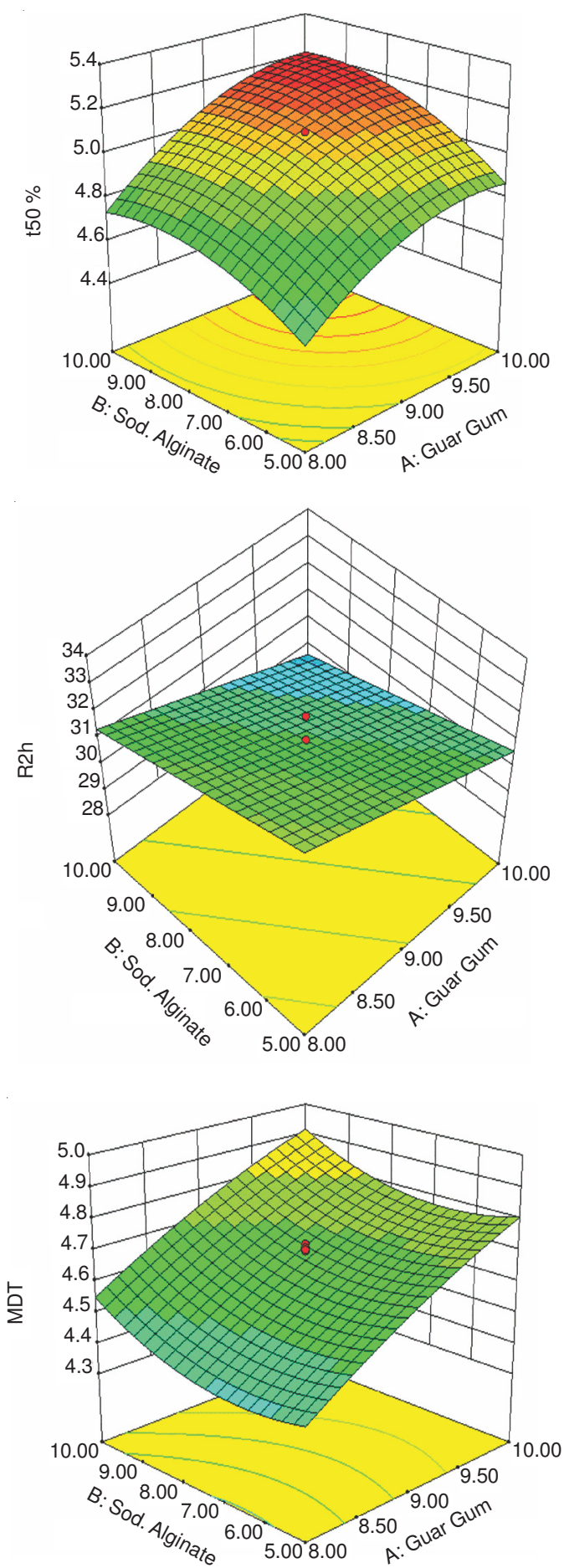

Fig. 4. Response surface plots for the response of $t_{50 \%}, R_{2} \mathrm{~h}$ and mean dissolution time in the change in independent variables

plots which has the highest desirability near to 1.0. The extensive grid and feasibility searches provided the optimum formulations and desired function response plot and overlay plot are as shown in Figs 6 and 7, where one solution was found with a highest desirability (prediction $=0.995$ ).

The optimum values of selected variables obtained using Design Expert soft ware were $9.31 \%$ guargum, $8.64 \%$ sodium alginate and $6.84 \% \mathrm{w} / \mathrm{w}$ sodium CMC. The final composition comprised $50 \%$ CT with $15 \%$ sodium bicarbonate, $2 \%$ magnesium stearate with the above quantity of polymers to form $400 \mathrm{mg} / \mathrm{tab}$. 

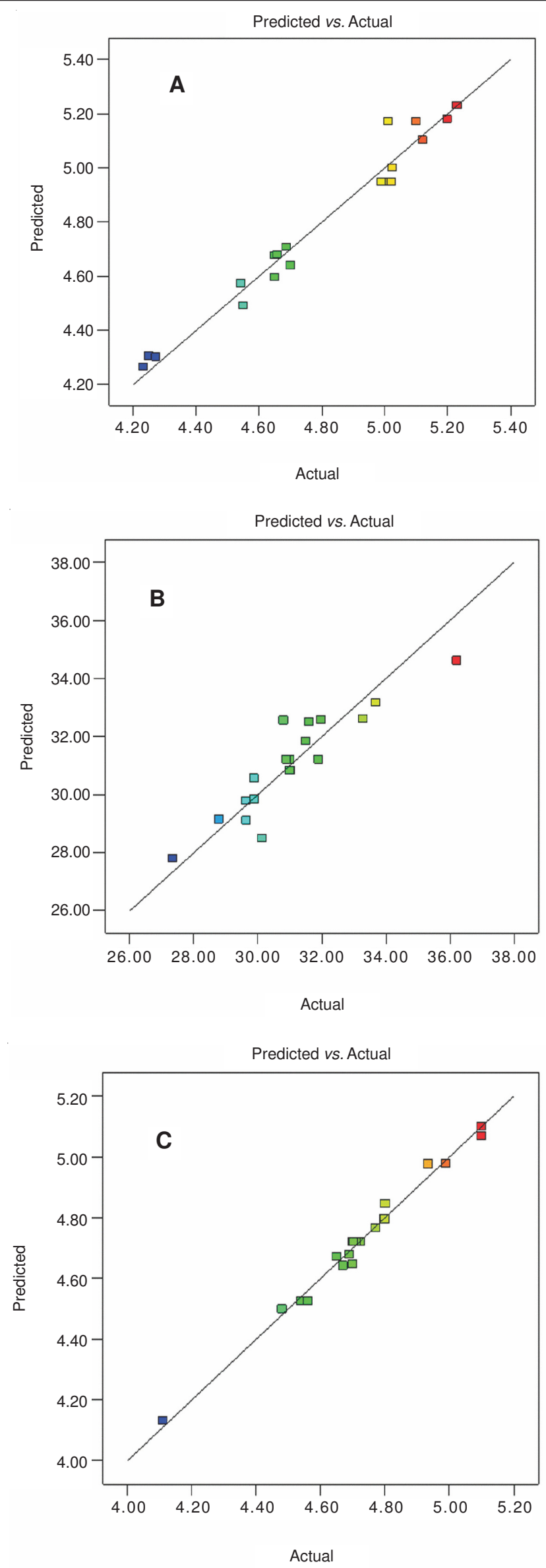

Fig. 5. Correlation graph of predicted versus actual data of for the response of $\mathrm{t}_{50} \%(\mathrm{~A}), \mathrm{R}_{2 \mathrm{~h}}$ (B) and mean dissolution time (C)

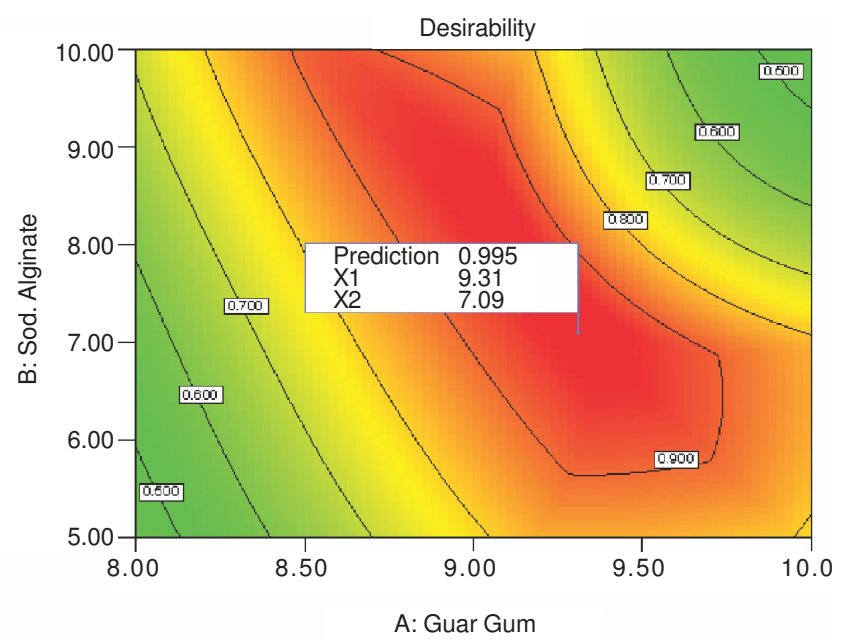

Fig. 6. Desirability for optimization of gastric floating tablets of CT. (A) concentration of guar gum (\%) and (B) concentration of sod. aiginate $(\%$, w/w) with $6.84 \%$ of sod. CMC

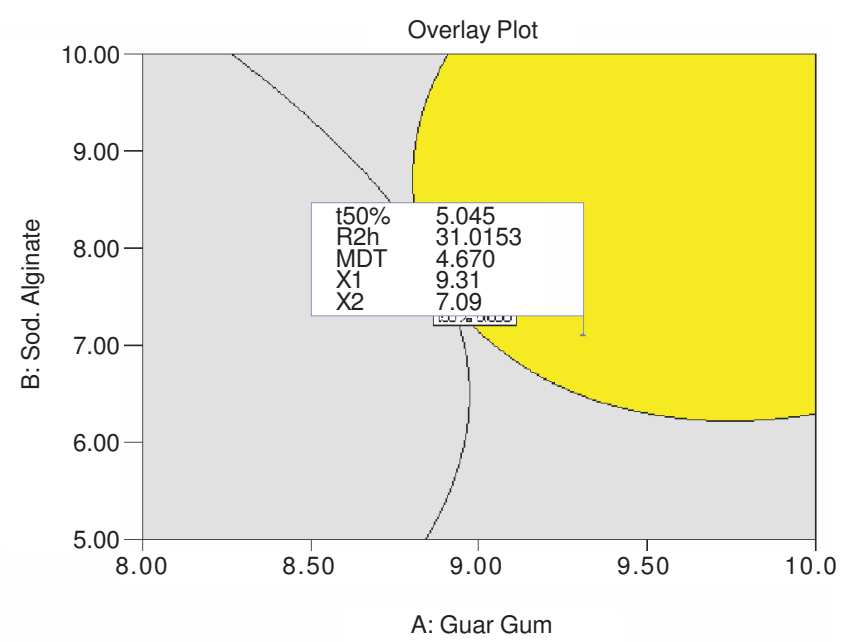

Fig. 7. Overlay plot for optimization of gastric floating tablets of CT. (A) concentration of guar gum (\%) and (B) concentration of sod. aiginate $(\%$, w/w) with $6.84 \%$ of sod. CMC

Evaluation and validation of the optimized formulation: The statistically optimized formulation (XG21) fulfilled all the physicochemical criteria. In vitro buoyancy and dissolution studies were carried out on the prepared optimized formulation to verify the theoretical prediction. The in vitro time required for $50 \%$ drug released $\left(\mathrm{t}_{50} \%\right)$ is $5.5 \mathrm{~h}$ which is in close agreement with the model predictions (Table-7). The relative errors $(\%)$ between the predicted and experimental values for each response were calculated and the values found to be within $\pm 5 \%$. The experimental values were in agreement with the predicted values confirming the predictability and validity of the model. The optimized formulation gave $t_{50}$, $\mathrm{R}_{2 \mathrm{~h}}$, MDT values of $4.982 \mathrm{~h}, 30.738 \%$ and $4.644 \mathrm{~h}$, respectively. Drug release from the optimized formulation followed Higuchi model with a non-Fickian diffusion mechanism.

FTIR study: IR spectra of pure drug and optimized formulations are given in Fig. 8. The characteristic peaks of cefixime trihydrate at: $3563 \mathrm{~cm}^{-1}$ for O-H stretching, $3293 \mathrm{~cm}^{-1}$ for $\mathrm{N}-\mathrm{H}$ stretching, $1770 \mathrm{~cm}^{-1}$ for $\mathrm{C}=\mathrm{O}$ stretching, $1670 \mathrm{~cm}^{-1}$ for $\mathrm{C}=\mathrm{C}$ alkenes and $1541 \mathrm{~cm}^{-1}$ for $\mathrm{N}-\mathrm{O}$ (nitro compounds) etc. The results of the FTIR spectral analysis showed that the 


\begin{tabular}{ccccc}
\hline \multicolumn{5}{c}{ TABLE-7 } \\
\multicolumn{5}{c}{ COMPARISON OF PREDICTED AND OBSERVED RESPONSES } \\
\multicolumn{2}{c}{ FOR THE STATISTICALLY OPTIMIZED FORMULATIONXG21 } \\
\hline Formulations & Response & Observed & Predicted & Relative error \\
\hline \multirow{3}{*}{ XG21 } & $\mathrm{t}_{50 \%}(\mathrm{~h})$ & 4.982 & 5.045 & 1.240 \\
& $\mathrm{R}_{2 \mathrm{~h}}(\%)$ & 30.738 & 31.015 & 0.890 \\
& $\mathrm{MDT}(\mathrm{h})$ & 4.644 & 4.670 & 0.646 \\
\hline
\end{tabular}

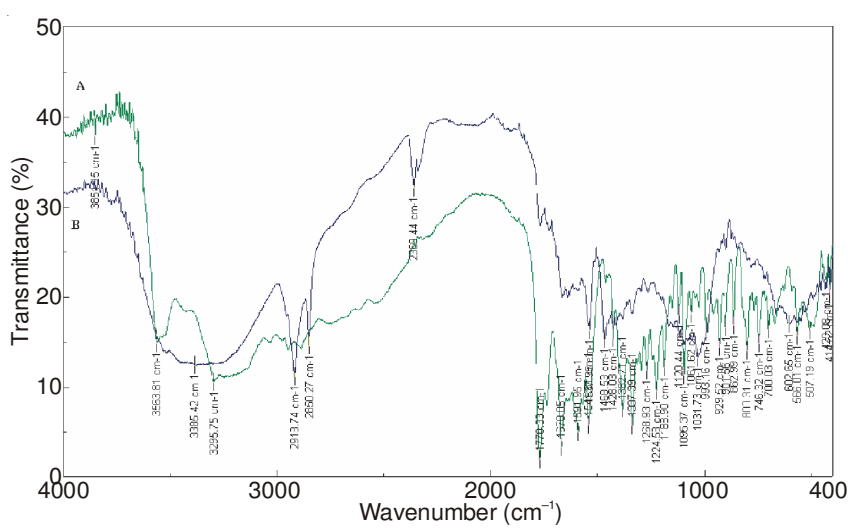

Fig. 8. FTIR spectra of cefixime trihydrate and the optimized formulation (XG21)

peaks and the pattern of the spectra were similar in all cases, which indicated that there was no chemical interaction or decomposition of cefixime trihydrate during the preparation of the tablets.

\section{Conclusion}

This study examines the preparation of a gastro retentive floating tablets containing cefixime trihydrate using the polymer guargum, sodium alginate gelling agent, sodium CMC channeling agent with sod. bicarbonate as gas generating agent. A systematic study using a central composite design revealed the most suitable content of above three formulations in the gastro retentive floating tablets. The optimized formulation fulfilled all the requirements of the target set and exhibited suitable values of $t_{50 \%}, R_{2 h}$, mean dissolution time. The present study clearly indicates the applicability of statistical optimization techniques to predict the composition of a formulation that gives optimum product parameters.

\section{ACKNOWLEDGEMENTS}

The authors are grateful to Lincon Pharma, Ahmbdabad, India for providing the samples.

\section{REFERENCES}

1. S.C. Porter and I. Ghebre-Bellassie, Key Factors in the Development of Modified-Release Pellets, In Multi Particulate Oral Drug Delivery, Ghebre-Bellassie, Marcel Dakker, New York, edn. 1, pp. 217-284 (1994).

2. J. Chen, W.E. Blevins, H. Park and K. Park, J. Control. Rel., 64, 39 (2000).

3. S. Arora, J. Ali, A. Ahuja, R.K. Khar and S. Baboota, AAPS Pharm. Sci. Technol., 6, 372 (2005).

4. G. Ponchel and J.M. Irache, Adv. Drug Del. Rev., 34, 191 (1998).

5. S.S. Davis, A.F. Stockwel, M.J. Taylor, J.G. Hardy, D.R. Walley and C.G. Wilso, Pharm. Res., 3, 208 (1986).

6. S.L. Sweetman, Martindale, Complete Drug Release, Published by Pharmaceutical Press, UK, edn. 33, p. 166 (2002).

7. C. Anthony, M. Mofft, D. Osselton and B. Widdep, Clark Analysis of Drugs and Poisons, Published by Pharmaceutical Press of Great Britain, edn. 3, Vol. 2, pp. 763-64 (2004).

8. G.P.E. Box and K.B. Wilson, J. Royal Stat. Soc. Ser B, 1391 (1951).

9. M. Rosa, H. Zia and T. Rhodes, Int. J. Pharm., 105, 65 (1994).

10. R. Korsmeyer, R. Gurny and N. Peppas, Int. J. Pharm., 15, 25 (1983).

11. T.P. Hadjiioannou, G.D. Christrian and M.A. Kouparis, Quantitative Calculation in Pharmaceutical Practice and Research, New York, KY; VCH Publishers Inc., pp. 343-348 (1993).

12. D.W. Bourne, Pharmacokinetics. In eds.: G.S. Banker and G.T. Rhodes, Modern Pharmaceutics Marcel Dakker, Inc., New Work, edn. 4, pp. 67-92 (2002).

13. T. Higuchi, J. Pharm. Sci., 52, 1145 (1963).

14. A.W. Hixson and J.H. Crowell, Ind. Eng. Chem., 23, 923 (1931).

15. R.W. Korsmeyer, R. Gurny, E. Doelker, P. Buri and N.A. Peppas, Int. J. Pharm., 15, 25 (1983).

16. J. Siepmann and N.A. Peppas, Adv. Drug. Deliv. Rev., 48, 139 (2001).

17. P. Costa and J.M.S. Lobo, Eur. J. Pharm. Sci., 13, 123 (2001).

18. K. Chaturvedi, S. Umadevi and S. Vaghani, Sci. Pharm., 78, 927 (2010).

19. M.V. Srikanthn, N.S. Rao, S.A. Sunil, B.J. Ram and V.R.M. Kolapalli, Acta Pharm. Sin. B, 2, 60 (2012).

20. G.T. Macfarlane, S. Hay, S. Macfarlane and G.R. Gibson, J. Appl. Bacteriol., 68, 179 (1990). 